\title{
Lipids and its Metabolism
}

\author{
Varshil Mehta ${ }^{1 *}$ and Kavya Bhatt ${ }^{2}$ \\ ${ }^{1}$ MGM Medical College, India \\ ${ }^{2}$ Santosh Medical College, India
}

Submission: February 07, 2017; Published: April 05, 2017

*Corresponding author: Varshil Mehta, MGM Medical College, Navi Mumbai-410209, India, Email: varshil91@gmail.com

\section{Abstract}

The main biological function of the lipids includes storing energy, signaling, and acting as structural components of cell membrane Lipids, such as cholesterol and triglycerides, are insoluble in plasma and circulating lipids are carried in lipoproteins to various tissues for energy utilization, lipid deposition, steroid hormone production, and bile acid formation. This review article will present the different types, functions and metabolism of the lipids.

Keywords: Lipid profile; Cholesterol; HDL; VLDL; LDL

\section{Cholesterol}

Cholesterol is designated as 3-betahydroxy-5, 6-cholestene. Cholesterol is widely distributed in all the cells of the body, particularly abundant in nervous tissues. Higher concentration of cholesterol is found in brain, liver, kidney, adipose tissue and suprarenal glands in both free and esterified forms. In plasma, esterified form comprises $65-75 \%$ and in tissues, free form dominates [1]. Liver appears to be chief source of endogenous cholesterol but it is also synthesized in adrenals, intestinal mucosa and brain. Dietary sources of cholesterol are mainly from food of animal origin.

Greater part of cholesterol of the body arises by synthesis (about $1 \mathrm{gm} /$ day), whereas $0.3 \mathrm{gm} /$ day is provided by the average diet. Virtually all tissues containing nucleated cells are capable of synthesizing cholesterol, particularly the liver, adrenal cortex, skin, intestine, testes, etc. In humans, the total plasma cholesterol is about $200 \mathrm{mg} / \mathrm{dl}$. The greater part is found in esterified form [2,3]. It is transported as lipoproteins in plasma. Higher proportion of it is found in LDL, to some extent in VLDL and HDL. Cholesterol in diet is absorbed from the intestine. Along with other lipids, including the cholesterol synthesized in the intestine are incorporated in to Chylomicrons and VLDL.

Approximately half of the cholesterol eliminated from the body is excreted in the faeces after conversion into bile salts. The remainder is excreted as neutral steroids. Much of the cholesterol secreted in the bile is reabsorbed. It is believed that the cholesterol that serves as precursors for the faecal sterol is derived from the intestinal mucosa [4]. A large portion of biliary excretion of bile salts is reabsorbed in to the portal circulation, taken up by the liver and re-secreted in the bile. This is known as entero hepatic circulation. The bile salts, which are not reabsorbed, are excreted in faeces.

Serum cholesterol levels have been given special attention as it gives direct evidence of various metabolic disorders and development of atherosclerosis. Elevated cholesterol concentration is considered prime risk factor for coronary heart disease. The Framingham study shows linear increase in coronary risk with increment in total plasma cholesterol concentration from $180 \mathrm{mg} / \mathrm{dl}$ upwards.

\section{Triglycerides}

They form the major bulk of the diet and major fraction of natural fats. Triglycerides are formed by combination of one glycerol molecule with 3 molecules of fatty acids, which may be same or different. The chief site of synthesis of triglycerides is liver and adipose tissue via glycerol phosphate pathway [5]. In plasma they are contained in VLDL.

The ingested triglycerides are converted in to low grade triglycerides, free fatty acids and mono glycerides by pancreatic lipase. These fatty acids and mono glycerides pass in to intestinal mucosal cells and are re-esterified to triglycerides, which are then incorporated with lipoproteins 
and carried in blood, contained in chylomicrons. These chylomicrons and VLDL are cleared from plasma by the action of lipoprotein lipases, forming FFA and LDL [6]. The FFA binds loosely with plasma albumin and has high turnover rate (halflife 2-3 minute). Quite a few amino acids may yield acetyl CoA, which may contribute to triglyceride synthesis. Hence excess of protein is stored as triglycerides.

\section{Lipoproteins}

The lipoprotein consists of esterified and unesterified cholesterol, triglycerides, phospholipids, and protein. Based on the physicochemical characteristics of lipoproteins, these particles have been classified by their lipoprotein subclass size and concentrations [7]. There are five major lipoproteins, each of which has a different function.

\section{Chylomicrons}

Chylomicrons are very large particles that carry dietary lipid. They are associated with a variety of apolipoproteins, including A-I, A-II, A-IV, B-48, C-I, C-II, C-III, and E.

\section{Very low density lipoprotein}

Very low density lipoprotein (VLDL) carries endogenous triglycerides and to a lesser degree cholesterol. The major apolipoproteins associated with VLDL are B-100, C-I, C-II, C-III, and E.

\section{Intermediate density lipoprotein}

Intermediate density lipoprotein (IDL) carries cholesterol esters and triglycerides. It is associated with apolipoproteins B-100, C-III, and E.

\section{Low density lipoprotein}

Low density lipoprotein (LDL) carries cholesterol esters and is associated with apolipoproteins B-100 and C-III.

\section{High density lipoprotein}

High density lipoprotein (HDL) also carries cholesterol esters. It is associated with apolipoproteins A-I, A-II, C-I, C-II, C-III, D, and E.

\section{Apolipoproteins}

Understanding the major functions of the different apolipoproteins is important clinically, because defects in apolipoprotein metabolism lead to abnormalities in lipid handling [8].

The assembly and secretion of apolipoprotein B containing lipoproteins in the liver and intestines is dependent upon microsomal triglyceride transfer protein, which transfers lipids to apolipoprotein B. In one study, apolipoprotein B and microsomal transfer protein genes were expressed in the human heart, strongly suggesting that the heart synthesizes and secretes apolipoprotein B containing lipoproteins [9]. This may represent a pathway of «reverse triglyceride transport» by which the cardiac myocytes can unload surplus fatty acids not required for fuel.

a) A-I-Structural protein for HDL; activator of lecithincholesterol acyltransferase (LCAT).

b) A-II-Structural protein for HDL; activator of hepatic lipase.

c) A-IV-Activator of lipoprotein lipase (LPL) and LCAT.

d) B-100-Structural protein for VLDL, IDL, LDL, and Lp (a); ligand for the LDL receptor; required for assembly and secretion of VLDL.

e) B-48-Contains 48 percent of B-100; required for assembly and secretion of chylomicrons; does not bind to LDL receptor.

f) C-I-Activator of LCAT.

g) C-II-Essential cofactor for LPL.

h) C-III-Interferes with apo-E mediated clearance of triglyceride-enriched lipoproteins and remnants by cellular receptors, particularly in the liver [10] inhibits triglyceride hydrolysis by lipoprotein lipase and hepatic lipase [11] has multiple proatherogenic effects on the arterial wall, including interfering with normal endothelial function $[12,13]$.

i) D-May be a cofactor for cholesteryl ester transfer protein.

j) E-Ligand for hepatic chylomicron and VLDL remnant receptor, leading to clearance of these lipoproteins from the circulation ligand for LDL receptor. There are three different apo E alleles in humans: E2, which has cysteine residues at positions 112 and 158; E3, which occurs in 60 to 80 percent of Caucasians and has cysteine at position 112 and arginine at position 158; and E4, which has arginine residues at positions 112 and 158 [14]. These alleles encode for a combination of apo E isoforms that are inherited in a codominant fashion. Compared to apo E3, apo E2 has reduced affinity and apo $\mathrm{E} 4$ has enhanced affinity for the LDL (apo B/E) receptor. These isoforms are important clinically because apo E2 is associated with familial dysbetalipoproteinemia (due to less efficient clearance of VLDL and chylomicrons) and apo E4 is associated with an increased risk of hypercholesterolemia and coronary heart disease.

k) Apo (a) Structural protein for Lp (a); inhibitor of plasminogen activation on Lp (a).

Lipoprotein metabolism can be divided into exogenous and endogenous pathways. The exogenous pathway starts with the intestinal absorption of dietary cholesterol and fatty acids. 
The mechanisms regulating the amount of dietary cholesterol that is absorbed are unknown (Figure 1).

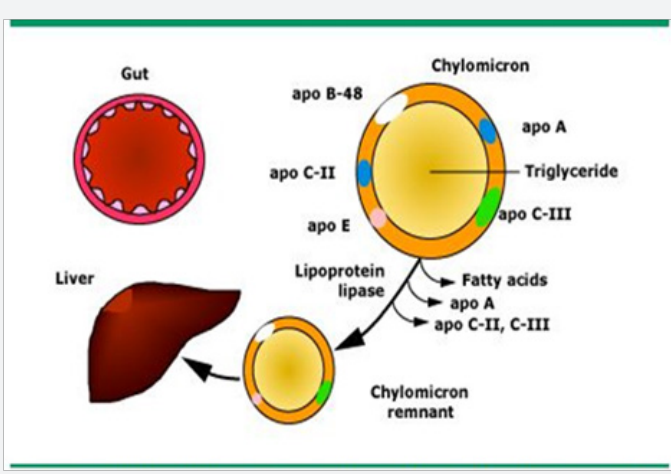

Figure 1: Endogenous Pathway of Lipid Metabolism.

Within the intestinal cell, free fatty acids combine with glycerol to form triglycerides, and cholesterol is esterified by acyl-coenzyme A: cholesterol acyltransferase (ACAT) to form cholesterol esters. The important role of ACAT was established in an animal model of ACAT deficiency, which found complete resistance to diet-induced hypercholesterolemia due to lack of cholesterol ester synthesis and reduced capacity to absorb cholesterol [15]. Triglycerides and cholesterol are assembled intracellularly as chylomicrons. The main apolipoprotein is B-48, but C-II and E are acquired as the chylomicrons enter the circulation. Apo B-48 permits lipid binding to the chylomicron but not does not bind to the low density lipoprotein receptor, thereby preventing premature clearance of chylomicrons from the circulation before they are acted upon by lipoprotein lipase (LPL).

Apo C-II is a cofactor for LPL that makes the chylomicrons progressively smaller, primarily by hydrolysing the core triglycerides and releasing free fatty acids. The free fatty acids are then used as an energy source, converted to triglyceride, or stored in adipose tissue. The end-products of chylomicron metabolism are chylomicron remnants that are cleared from the circulation by hepatic chylomicron remnant receptors for which apo E is a high-affinity ligand. The chylomicron remnants contain a smaller core of lipids that is enveloped by excess surface components. These surface constituents are transferred from the chylomicron remnant for the formation of high density lipoprotein.

The endogenous pathway of lipid metabolism begins with the synthesis of very low lipoprotein (VLDL) by the liver (Figure 2). VLDL particles contain a core of triglycerides (60 percent by mass) and cholesterol esters (20 percent by mass). Microsomal triglyceride transfer protein (MTP) is an intracellular lipid-transfer protein found in the endoplasmic reticulum. It is essential for the transfer of the lipid molecules (principally triglycerides) onto apolipoprotein (apo) B 100 in the liver $[16,17]$. The surface apo lipo proteins for VLDL apo C-II acts as a cofactor for lipoprotein lipase, apo C-III which inhibits this enzyme, and apo B-100 and E which serve as ligands for the apo lipo protein B/E (low density lipoprotein [LDL]) receptor [8]. In the absence of functional MTP, VLDL is not secreted into the circulation. The triglyceride core of nascent VLDL particles is hydrolysed by lipoprotein lipase. During lipolysis, the core of the VLDL particle is reduced, generating VLDL remnant particles (also called intermediate density lipoprotein [IDL]) that are depleted of triglycerides via a process similar to the generation of chylo micron remnants. Some of the excess surface components in the remnant particle, including phospholipid, unesterified cholesterol, and apo lipo proteins A, C and E, are transferred to high density lipoprotein (HDL).

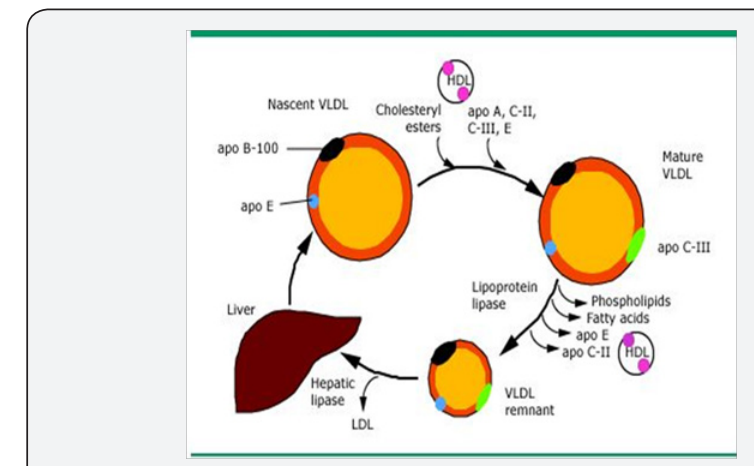

Figure 2: Endogenous pathway of lipid metabolism.

VLDL remnants can either be cleared from the circulation by the apo B/E (LDL) or the remnant receptors or remodelled by hepatic lipase to form LDL particles. There are four common sequence polymorphisms in the hepatic lipase gene promoter; the most frequent is a $C$ to $T$ substitution [18]. The presence of a $\mathrm{C}$ allele is associated with higher hepatic lipase activity; smaller, denser, and more atherogenic LDL particles, and inversely with lower levels of HDL cholesterol [19].

\section{Low density lipoprotein (LDL)}

LDL particles contain a core of cholesterol esters, lesser amounts of triglyceride, and are enriched in apolipoprotein B-100, which is the ligand for binding to the apo B/E (LDL) receptor. LDL can be internalized by hepatic and non-hepatic tissues. Hepatic LDL cholesterol can be converted to bile acids and secreted into the intestinal lumen. LDL cholesterol internalized by non-hepatic tissues can be used for hormone production, cell membrane synthesis, or stored in the esterified form.

The internalization of LDL is regulated by cellular cholesterol requirements via negative feedback control of apo B/E (LDL) receptor expression [20]. Cells in positive cholesterol balance, for example, suppress apo B/E (LDL) receptor expression. On the other hand, decreased activity of HMG CoA reductase, the enzyme that controls the rate of de novo cholesterol synthesis by the cell, leads sequentially to a fall in cell cholesterol, increased expression of apo B/E (LDL) 
receptors, enhanced uptake of cholesterol from the circulation, and a reduction in the plasma cholesterol concentration.

Chemically-modified LDL such as oxidized LDL can also enter macrophages and some other tissues through the unregulated scavenger receptor. This pathway can result in excess accumulation of intracellular cholesterol and the formation of foam cells, which contribute to the formation of atheromatous plaques.

The importance of the LDL receptor in the regulation of cholesterol metabolism has been demonstrated in both experimental animals and humans. Knockout of the LDL receptor in transgenic mice leads to a substantial elevation in total cholesterol levels; a defect that can be reversed by restoring the LDL receptor gene [21]. In humans, familial hypercholesterolemia is often associated with a defect in the LDL receptor [22].

\section{High density lipoprotein (HDL)}

Formation and metabolism of HDL involves the following steps (Figure 3) [8,23]:

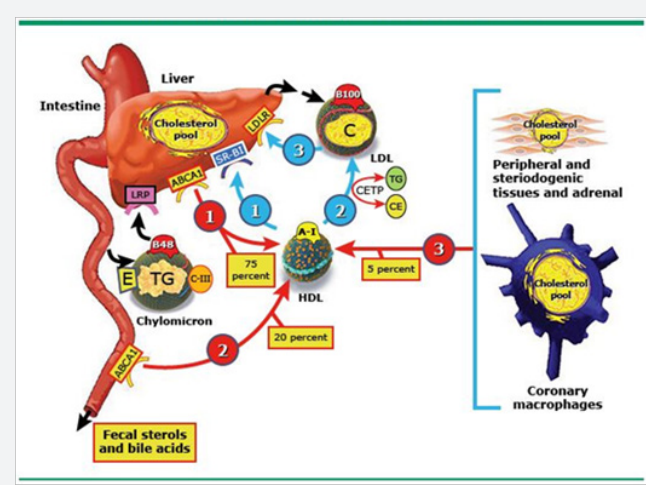

LRP: Lipoprotein Receptor-Receptor Protein; SR-BI: Scavenger Receptor Class B Type I; LDL: Low-Density Lipoprotein; LDLR: LDL Receptor; CETP: Cholesteryl Ester Transfer Protein; Tg and TG: Triglycerides; CE: Cholesterol Efflux

Figure 3: Metabolic pathways that regulation.

i. Hepatic and intestinal synthesis of small nascent HDL particles composed of phospholipid and apolipoproteins.

ii. Then, there is procurement of surface components (phospholipids, cholesterol and apolipoproteins) from triglyceride-depleted chylomicron and VLDL remnants.

iii. Acquisition of free cholesterol from tissue sites and other lipoproteins, as the initial HDL particles contain relatively little cholesterol.

iv. Apolipoprotein A-I on the surface of HDL plays a central role in this process. It serves as a signal transduction protein to mobilize cholesterol esters from intracellular pools. After diffusion of free (unesterified) cholesterol onto HDL, the cholesterol is esterified to cholesterol esters by lecithin- cholesterol acyltransferase (LCAT), a plasma enzyme that is activated primarily by apolipoprotein A-I. By a similar mechanism, HDL can act as an acceptor for cholesterol released during lipolysis of triglyceride-containing lipoproteins.

Cholesterol efflux regulatory protein also appears to play an important role in the uptake of cellular cholesterol by HDL by promoting the transfer of intracellular cholesterol to the cell membrane $[24,25]$. Mutations in the gene encoding for this protein, $A B C 1$, are associated with low serum HDL concentrations in familial HDL deficiency and Tangier disease.

Lipid transfer proteins, such as cholesteryl ester transfer protein, facilitate movement of these newly synthesized cholesterol esters to apolipoprotein B-containing lipoproteins (VLDL, IDL, and LDL). The cholesterol can then be delivered to the tissues for steroid synthesis or storage. The net effect of the last two steps is the removal of excess cholesterol from cells, which constitutes most of the anti-atherogenic effect of HDL.

\section{Lipoprotein(a)}

Lipoprotein (a) or Lp (a) is a specialized form of LDL that is assembled extra cellularly from Apo lipoprotein (a) and LDL. Apo (a) linked to apolipoprotein B-100 on the surface of LDL by disulfide bridges. The formation of apo (a): apo B complexes require an LDL particle of a certain morphology and composition. The structural integrity of LDL, and therefore Lp (a) formation, are modulated by LCAT [26]. The apo (a) chain contains five domains known as kringles [27]. The fourth kringle contains regions that are homologous with the fibrinbinding domains of plasminogen. Through this structural similarity to plasminogen, Lp (a) interferes with fibrinolysis by competing with plasminogen binding to plasminogen receptors, fibrinogen, and fibrin.

The net effect is impaired plasminogen activation and plasmin generation at the thrombus surface, leading to decreased thrombolysis [28,29]. Lp (a) can also bind to macrophages via a high-affinity receptor, possibly promoting foam cell formation and localization of $\mathrm{Lp}$ (a) at atherosclerotic plaques [30].

\section{Very Low Density Lipoprotein (VLDL)}

Most of the plasma VLDL are hepatic in origin and are vehicles of triglyceride transport from the liver to extra hepatic tissues. Ribosomes on rough endoplasmic reticulum of liver cell synthesize Apo protein B-100. Lipids are incorporated with B-100 lipoprotein to form VLDL. It is secreted by the hepatic cells through fenestrated sinusoidal epithelium in to the space of Disse and enters the blood stream. These nascent VLDLs, once in circulation take up apo-protein $\mathrm{C}$ and apo-protein $\mathrm{E}$ from HDL, which they are devoid of.

Liver does not catabolise nascent VLDL. The lipoprotein lipase hydrolyses VLDL through mono and di-acyl glycerol to 
free fatty acids and glycerol. Then, free fatty acids are taken up by the tissues. Lipoprotein lipase requires phospholipids and apo-protein $\mathrm{C}$ as cofactors, present on VLDL. Reaction with lipoprotein lipase results in loss of $90 \%$ of Triglycerol, apo-protein A and apo-protein C. The percentage amount of cholesterol and its esters almost doubles. Apo-protein $\mathrm{E}$ is retained by remnants.

\section{Lipid Profile and its Components}

A standard serum lipid profile measures the concentration of total and HDL-cholesterol (HDL-C) as well as the triglycerides. With these values, the LDL cholesterol (LDL-C) concentration can be estimated.

\section{Total and HDL-C}

Serum total and HDL-C are measured directly and can be obtained in fasting or non-fasting individuals; there are only small, clinically insignificant differences in these values between measurements in the fasting or non-fasting state [31].

The total cholesterol can vary by 4 to 11 percent within an individual due to multiple factors including stress, minor illness, and posture [32]. Values may also vary between different laboratories, with data suggesting that a single measurement of serum cholesterol can vary as much as 14 percent $[32,33]$. Thus, in an individual with a «true» serum cholesterol concentration of $200 \mathrm{mg} / \mathrm{dL}(5.2 \mathrm{mmol} / \mathrm{L})$, the range of expected values is 172 to $228 \mathrm{mg} / \mathrm{dL}$ ( 4.5 to $5.9 \mathrm{mmol} / \mathrm{L}$ ) $[33,34]$. These observations suggest that more than one measurement of total cholesterol should be obtained when treatment considerations demand a precise determination. Serum HDL-C may demonstrate even greater variability [35].

\section{LDL-cholesterol}

Friedewald equation: LDL-C reported in the lipid profile is generally calculated using the Friedewald formula, which states:

LDL-C = Total cholesterol - VLDL-cholesterol (VLDL-C) HDL-C [36].

The total cholesterol in plasma or serum is the sum of cholesterol found in each of the VLDL, HDL, and LDL lipoprotein particle types. The Friedewald formula is applied to lipid values measured in the fasted state. In a non-fasting patient, the contribution of post-prandial chylomicrons to the total lipoprotein pool makes the formula much less accurate.

VLDL associated cholesterol is approximated by dividing the measured total triglyceride level by 5 . With the measured total and HDL-C and triglyceride, an approximate LDL-C can be calculated. There are, however, several sources of error involved in the estimation of LDL-C using the Friedewald formula. The formula is valid only if the total triglyceride concentration is less than $400 \mathrm{mg} / \mathrm{dL}(4.516 \mathrm{mmol} / \mathrm{L})$. In patients with more pronounced hypertriglyceridemia, LDL-C levels must be measured directly (direct LDL), by ultra centrifugal single spin analysis or immune precipitation technique.

The estimated LDL-C concentration is also influenced by the method error from each of the independent lipid measurements (total cholesterol, triglycerides, and HDLcholesterol). The calculation of VLDL-C (from triglycerides) underestimates the cholesterol content of the atherogenic, intermediate density lipoprotein (IDL), and VLDL remnants. The estimated LDL-C concentration includes cholesterol contained in other lipoproteins, such as lipoprotein(a) and lipoprotein-X.

\section{References}

1. Kortenoever M (1960) Physiological changes in pregnancy. 21: 443445 .

2. Kaaja RJ, Greer IA (2005) Manifestations of chronic disease during pregnancy. JAMA 294(21): 2751-2757.

3. Sattar N, Greer IA (2002) Pregnancy complications and maternal cardiovascular risk: opportunities for intervention and screening? BMJ 325(7356): 157-160

4. Buchanan TA, Xiang AH (2005) Gestational diabetes mellitus. J Clin Invest 115(3): 485-491.

5. Hollander MH, Paarlberg KM, Huisjes AJ (2007) Gestational diabetes: a review of the current literature and guidelines. Obstet Gynecol Surv 62(2): 125-136.

6. Frishman WH, Veresh M, Schlocker SJ, Tejani N (2006) Pathophysiology and medical management of systemic hypertension in preeclampsia. Curr Hypertens Rep 8(6): 502-511.

7. Rosenson RS, Brewer HB, Chapman MJ, Fazio S, Hussain MM, et al. (2011) HDL measures, particle heterogeneity, proposed nomenclature, and relation to atherosclerotic cardiovascular events. Clin Chem 57(3): 392-410.

8. Rader DJ, Hoeg JM, Brewer HB (1994) Quantitation of plasma apolipoproteins in the primary and secondary prevention of coronary artery disease. Ann Intern Med 120(12): 1012-1025.

9. Nielsen LB, Véniant M, Borén J, Raabe M, Wong JS, et al. (1998) Genes for apolipoprotein $\mathrm{B}$ and microsomal triglyceride transfer protein are expressed in the heart: evidence that the heart has the capacity to synthesize and secrete lipoproteins. Circulation 98(1): 13-16.

10. de Silva HV, Lauer SJ, Wang J, Simonet WS, Weisgraber KH, et al. (1994) Over expression of human apolipoprotein C-III in transgenic mice results in an accumulation of apolipoprotein B48 remnants that is corrected by excess apolipoprotein E. J Biol Chem 269(3): 2324-2335.

11. Ginsberg HN, Le NA, Goldberg IJ, Gibson JC, Rubinstein A, et al. (1986) Apolipoprotein B metabolism in subjects with deficiency of apolipoproteins CIII and AI. Evidence that apolipoprotein CIII inhibits catabolism of triglyceride-rich lipoproteins by lipoprotein lipase in vivo. J Clin Invest 78(5): 1287-1295.

12. Tall AR (1990) Plasma high density lipoproteins. Metabolism and relationship to atherogenesis. J Clin Invest 86(2): 379-384.

13. Mendivil CO, Rimm EB, Furtado J, Chiuve SE, Sacks FM (2011) Lowdensity lipoproteins containing apolipoprotein C-III and the risk of coronary heart disease. Circulation 124(19): 2065-2072.

14. Davignon J, Gregg RE, Sing CF (1988) Apolipoprotein E polymorphism and atherosclerosis. Arteriosclerosis 8(1): 1-21. 
15. Buhman KK, Accad M, Novak S, Choi RS, Wong JS, et al. (2000) Resistance to diet-induced hypercholesterolemia and gallstone formation in ACAT2-deficient mice. Nat Med 6(12): 1341-1347.

16. Raabe M, Véniant MM, Sullivan MA, Zlot CH, Björkegren J, et al. (1999) Analysis of the role of microsomal triglyceride transfer protein in the liver of tissue-specific knockout mice. J Clin Invest 103(9): 12871298.

17. Wetterau JR, Lin MC, Jamil H (1997) Microsomal triglyceride transfer protein. Bio chim Biophys Acta 1345(2): 136-150.

18. Tahvanainen E, Syvanne M, Frick MH, Murtomaki-Repo S, Antikainen M, et al. (1998) Association of variation in hepatic lipase activity with promoter variation in the hepatic lipase gene. The LOCAT Study Invsestigators. J Clin Invest 101(5): 956-960.

19. Zambon A, Deeb SS, Brown BG, Hokanson JE, Brunzell JD (2001) Common hepatic lipase gene promoter variant determines clinical response to intensive lipid-lowering treatment. Circulation 103(6): 792-798.

20. Brown MS, Goldstein JL (1986) A receptor-mediated pathway for cholesterol homeostasis. Science 232(4746): 34-47.

21. Ishibashi S, Brown MS, Goldstein JL, Gerard RD, Hammer RE, et al. (1993) Hypercholesterolemia in low density lipoprotein receptor knockout mice and its reversal by adenovirus-mediated gene delivery. J Clin Invest 92(2): 883-893.

22. Hobbs HH, Russell DW, Brown MS, Goldstein JL (1990) The LDL receptor locus in familial hypercholesterolemia: mutational analysis of a membrane protein. Annu Rev Genet 24: 133-170.

23. Rosenson RS, Brewer HB, Davidson WS (2012) Cholesterol efflux and atheroprotection: advancing the concept of reverse cholesterol transport. Circulation 125(15): 1905-1919.

24. Marcil M, Brooks-Wilson A, Clee SM (1999) Mutations in the ABC1 gene in familial HDL deficiency with defective cholesterol efflux. Lancet 354(9187): 1341-1346.

25. Marcil M, Yu L, Krimbou L (1999) Cellular cholesterol transport and efflux in fibroblasts are abnormal in subjects with familial HDL deficiency. Arterioscler Thromb Vasc Biol 19(1): 159-169.

This work is licensed under Creative Commons Attribution 4.0 License

DOI: $10.19080 /$ JOCCT.2017.04.555635
26. Steyrer E, Durovic S, Frank S, Giessauf W, Burger A, et al. (1994) The role of lecithin: cholesterol acyltransferase for lipoprotein (a) assembly. Structural integrity of low density lipoproteins is a prerequisite for $\mathrm{Lp}$ (a) formation in human plasma. J Clin Invest 94(6): 2330-2340.

27. Berge KE, Tian H, Graf GA, Yu L, Grishin NV, et al. (2000) Accumulation of dietary cholesterol in sitosterolemia caused by mutations in adjacent ABC transporters. Science 290(5497): 1771-1775.

28. Loscalzo J, Weinfeld M, Fless GM, Scanu AM (1990) Lipoprotein(a), fibrin binding, and plasminogen activation. Arteriosclerosis 10(2): 240-245.

29. Palabrica TM, Liu AC, Aronovitz MJ (1995) Antifibrinolytic activity of apolipoprotein(a) in vivo: human apolipoprotein(a) transgenic mice are resistant to tissue plasminogen activator-mediated thrombolysis. Nat Med 1(3): 256-259.

30. Zioncheck TF, Powell LM, Rice GC, Eaton DL, Lawn RM (1991) Interaction of recombinant apolipoprotein(a) and lipoprotein(a) with macrophages. J Clin Invest 87(3): 767-771.

31. Craig SR, Amin RV, Russell DW (2000) Blood cholesterol screening influence of fasting state on cholesterol results and management decisions. J Gen Intern Med 15(6): 395-399.

32. Cooper GR, Myers GL, Smith SJ, Schlant RC (1992) Blood lipid measurements. Variations and practical utility. JAMA 267(12): 16521660.

33. US Preventive Services Task Force (1996) Guide to clinical preventive services. (2):15.

34. Belsey R, Baer DM (1990) Cardiac risk classification based on lipid screening. JAMA 263(9): 1250-1252.

35. Bachorik PS, Cloey TA, Finney CA, Lowry DR, Becker DM (1991) Lipoprotein-cholesterol analysis during screening: accuracy and reliability. Ann Intern Med 114(9): 741-747.

36. Friedewald WT, Levy RI, Fredrickson DS (1972) Estimation of the concentration of low-density lipoprotein cholesterol in plasma, without use of the preparative ultracentrifuge. Clin Chem 18(6): 499502 .

\begin{tabular}{l} 
Your next submission with Juniper Publishers \\
will reach you the below assets \\
- Quality Editorial service \\
- Swift Peer Review \\
- Reprints availability \\
- E-prints Service \\
- Manuscript Podcast for convenient understanding \\
- Global attainment for your research \\
- Manuscript accessibility in different formats \\
( Pdf, E-pub, Full Text, Audio) \\
- Unceasing customer service \\
Track the below URL for one-step submission \\
https://juniperpublishers.com/online-submission.php \\
\hline
\end{tabular}

